J. LIQ. CHROM. \& REL. TECHNOL., 25(1), 59-67 (2002)

\title{
SEMI-PREPARATIVE HPLC SEPARATION OF TERPENOIDS FROM THE SEED PODS OF HYMENAEA COURBARIL VAR. STILBOCARPA
}

\author{
R. T. Nogueira, S. C. N. Queiroz, and P. M. Imamura* \\ Department of Organic Chemistry, Chemistry Institute, \\ State University of Campinas-UNICAMP, Cx. Postal 6154, \\ 13083-970 Campinas, SP, Brazil
}

\begin{abstract}
Column chromatography of the ethyl acetate extract of the seed pod resin of Hymenaea courbaril var. stilbocarpa furnished a fraction containing a mixture of two new clerodanes and a known clerodane diterpene. Due to the similarity of the structures, they could not be separated by ordinary chromatography even using silica gel impregnated with $\mathrm{AgNO}_{3}$. Thus, an intense study was made in order to optimize the semipreparative separation of this mixture by HPLC (high performance liquid chromatograph) using several different stationary and mobile phases. The best conditions for separation of these diterpenes was on octadecyl-bonded silica with methanol:water:formic acid $(85: 15: 1, v / v / v)$ as mobile phase, flow rate at $2 \mathrm{~mL} / \mathrm{min}$, and
\end{abstract}

*Corresponding author. E-mail: imam@iqm.unicamp.br 
UV detection at $240 \mathrm{~nm}$. The fractions obtained were analyzed by gas chromatography-mass spectrometry (GC-MS).

\section{INTRODUCTION}

Hymenaea (Caesalpinoideae, Ditareae) is a genus widely distributed from Central America to South America, principally in the Amazon basin. (1) The trunk exudates a resin, which is locally used in folk medicine for treatment of wounds, bronchitis, and stomach disorders. (2) Analgesic and anti-inflammatory activities have also been reported for the hydroalcoholic extract of the bark. (3) Recently, an oily resin obtained from Copaifera bark, a species closely related to Hymenaea, showed inhibition of growth of Trypanosoma cruzi a protozoan which causes "Chagas' disease". This disease affects almost eight million of Brazilians and, as far as we know, there is, up to now, no suitable treatment for it. In addition, copaiba oil showed activity for prevention of skin cancer with the advantage of not being toxic. $(1,4)$

The acidic fraction of Hymenaea species extract is known to contain mainly diterpenes $(1,2,5-11)$ and our research group has isolated, during our earlier investigations, diterpenes belonging to the enantio-labdane series which are common in Hymenaea from the bark extract of $H$. stigonocarpa var. pubescens. (12) Continuing our interest in searching for new sources of diterpenes, for use as starting materials in organic synthesis, as well as for antimicrobial bioautographic assays (antifungal and antibacterial), we investigated the chemical composition of the seed pod resin of $H$. courbaril var. stilbocarpa. However, the isolation of these types of compounds is not easy, since their behavior in chromatographic separations is almost identical due to the similarity of their structures. According to the literature, and our previous studies, traditional methods such as vacuum distillation and preparative GC cannot be carried out without thermal degradation. Column liquid chromatography and thin layer chromatography (silica gel or silica gel impregnated with $\mathrm{AgNO}_{3}$ ) are time consuming and present a low resolution. (13)

The high performance liquid chromatography technique is well adapted to thermosensitive compounds like terpenoids and offers high resolution. (14-18) Thus, the goal of the present work is to describe the strategy used for the optimization of chromatographic conditions, in terms of mobile and stationary phases, for isolation by semipreparative HPLC of two new clerodanes ( 1 and 2 , Figure 1), and a known clerodane (3, Figure 1). Two other known compounds (4 and $\mathbf{5}$, Figure 1) were also isolated using traditional chromatographic methods. The structures of 1 and 2 were recently elucidated by ${ }^{1} \mathrm{H}$ and ${ }^{13} \mathrm{C}$ NMR analyses, including NOESY, HMBC, and HMQC experiments. (19) 

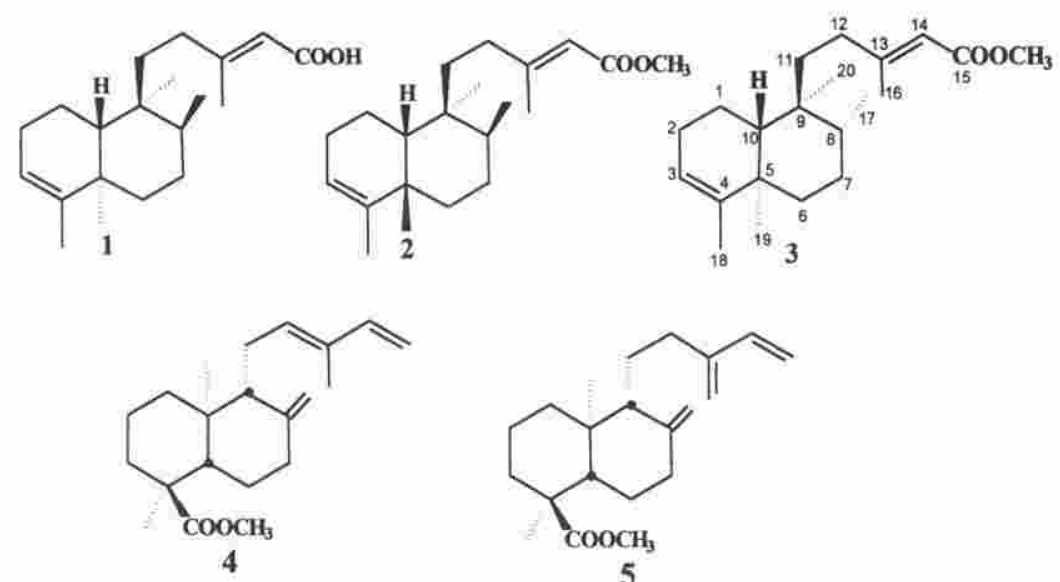

Figure 1. Structures of clerodanes isolated in this study: (-)-(5R,8S,9S,10R)-Cleroda3,13E-dien-15-oic acid (1), methyl (-)-(5S,8S,9S,10R)-Cleroda-3,13E-dien-15-oate (2); methyl (-)-kovalenate (3).

\section{EXPERIMENTAL}

\section{Diterpenoid Extraction and Pre-purification}

The seed pods of $H$. courbaril var. stilbocarpa were collected at Fazenda Santa Elisa, Campinas, São Paulo State, Brazil. The extract was prepared from fresh material according to methods previously described.(19) The ethyl acetate extract was submitted to column chromatography (silica gel) followed by preparative TLC on $\mathrm{SiO}_{2} / \mathrm{AgNO}_{3}(5 \%)$ and a fraction containing a mixture of the three compounds was submitted to HPLC analysis.

\section{High Performance Liquid Chromatography}

Several commercially prepacked semi-preparative columns were evaluated in this study: $250 \mathrm{~mm} \times 10 \mathrm{~mm}$ (i.d.) packed with Spherisorb silica (Regis), $5 \mu \mathrm{m}$; $300 \mathrm{~mm} \times 7.8 \mathrm{~mm}$ (i.d.) packed with Waters $\mu$-Bondapack $\mathrm{NH}_{2}, 10 \mu \mathrm{m}$; $250 \mathrm{~mm} \times 10 \mathrm{~mm}$ (i.d.) packed with Spherisorb octadecyl-bonded silica (ODS1) (Regis), $5 \mu \mathrm{m} ; 250 \mathrm{~mm} \times 10 \mathrm{~mm}$ (i.d.) packed with Spherisorb octadecylbonded silica (ODS-2) (Regis), $5 \mu \mathrm{m}$, all using a model 600E system controller (Waters). Injections were made through sample loops having volumes of $5 \mu \mathrm{L}$ for optimization and $100 \mu \mathrm{L}$ for semipreparative work, with a conventional Model 
7025 injection valve (Rheodyne). Detection was performed with a model 484 UV spectrophotometer (Waters) at $240 \mathrm{~nm}$. The flow rate was $2 \mathrm{~mL} / \mathrm{min}$. All measurements were carried out at room temperature. The chromatographic parameters, retention factor, $\mathrm{k}$, separation factor, $\alpha$, and resolution, Rs, were calculated manually.

\section{Gas Chromatography}

The solvent from the HPLC fractions was evaporated at room temperature. The residues were dissolved in diethyl ether and analyzed using a HewlettPackard capillary GC (Model HP 5890B series II) coupled to a quadrupole MS system (Model HP 5970) fitted with a $30 \mathrm{~m} \times 0.25 \mathrm{~mm}$ (i.d.) fused silica HP-5 column coupled to the source. The $\mathrm{GC}$ oven was programmed from 200 to $300^{\circ} \mathrm{C}$ at $3^{\circ} \mathrm{C} / \mathrm{min}$ with helium as carrier gas. Typical MS operating conditions were used and mass spectra were obtained by scanning from 40 to 400 a.m.u. The mass spectrometer was operated at $70 \mathrm{eV}$. Before analysis by GC/MS, the acid compounds were esterified previously with diazomethane.

\section{Solvents and Reagents}

Reagent grade ethyl acetate (Merck) was used for extraction of the diterpenoids from the seed pods. The mobile phases were optimized using the following HPLC grade solvents: acetonitrile (Merck), methanol (Mallinckrodt), n-hexane (Grupo Química), ethyl ether (Grupo Química), ethyl acetate (Grupo Química). The mobile phases were filtered through a $0.45 \mu \mathrm{m}$ filter and degassed by vacuum and an ultrasonic bath.

The additives used for preparation of the mobile phases were: formic acid (Vetec) and ammonium hydrogen sulfate (Aldrich). HPLC-quality water $\left(\mathrm{H}_{2} \mathrm{O}\right)$ was obtained by purification of in-house distilled water through a Milli-Q (Millipore) water purifier.

\section{RESULTS AND DISCUSSION}

The ethyl acetate extracts of seed pod resin from $H$. courbaril var. stilbocarpa, which consists of a complex mixture of sesquiterpenes $(28 \%)$ and diterpenes $(72 \%)$, was submitted to acidic and basic extractions. The acidic fraction containing diterpenes $\mathbf{1 - 5}$, was submitted to a combination of column chromatography (silica gel) followed by preparative TLC on $\mathrm{SiO}_{2} / \mathrm{AgNO}_{3}(5 \%)$ to give three fractions. Two of these were immediately esterified with $\mathrm{CH}_{2} \mathrm{~N}_{2}$ to 
furnish the corresponding methyl esters $\mathbf{4}$ and 5, respectively.(19) A third fraction, containing the mixture of compounds $\mathbf{1 - 3}$, was submitted to further purification by semipreparative HPLC, as discussed in this paper. The structures of three clerodane diterpenes are depicted in Figure 1.(19) The separation of these types of compounds is not easy, due to their closely related structures, and this type of analysis presents tantalizing challenges to the analysts. The minimum changes in their molecular polarities and hydrophobicities appear to be governed by spatial orientation of the methyl groups (steric effects). In this study, two chromatographic techniques were used: normal and reversed-phase chromatography.

The normal-phase (silica and $\mathrm{NH}_{2}$ stationary phases) HPLC retention behavior of these three compounds, using $n$-hexane, $n$-hexane-ethyl ether, and $n$ hexane-ethyl acetate as a mobile phase, was indistinguishable, and without sufficient separation. So, reversed-phase chromatography was investigated.

A variety of chromatographic conditions were evaluated for the separation of the mixture. Variation of the retention factor $(\mathrm{k})$, separation factors $(\alpha)$, and the resolution (Rs) were calculated for the different conditions, as shown in Table 1. The results obtained for binary solvent systems $\left(\mathrm{MeOH} / \mathrm{H}_{2} \mathrm{O}\right)$ on ODS 1 for both the methyl esters and the acidic forms, gave unsatisfactory resolution for all components. Thus, this complex separation requires the use of modifiers in the mobile phases to explore the possibility of enhancing the separation factor.

A small amount of ammonium hydrogen sulfate $(0.005 \mathrm{~mol} / \mathrm{L})$ was added to the mobile phase $\left(\mathrm{MeOH}: \mathrm{H}_{2} \mathrm{O}\right.$ ) and, with this, it was possible to observe resolution of the three components through the ion-pair interaction. However, it was very difficult to remove the salt residues from the collected fractions so that these substances could be characterized by spectroscopic methods. In order to avoid this problem, a small percentage $(1 \%)$ of formic acid, which is volatile and easily removed by evaporation, was added to the mobile phase $\left(\mathrm{MeOH} / \mathrm{H}_{2} \mathrm{O}\right.$ or $\mathrm{ACN} / \mathrm{H}_{2} \mathrm{O}$ ). Inspection of the HPLC data in Table 1 indicates that $\alpha$ values for adjacent components were influenced by addition of this acid to the mobile phase, furnishing resolution, Rs, of the three components indicating that these compounds are present in non-dissociated forms. This process, called "ionic suppression," has been widely used for the analysis of organic acids and consists of reducing the ionization of solutes by modification of the $\mathrm{pH}$ of the mobile phase.

To assess the effect of increasing hydrophobicity, two types of Spherisorb stationary phase were employed: ODS 1 (end-capped) and ODS 2 (not endcapped), with $\%$ of carbon 6.2 and 11.5 , respectively. Results of HPLC experiments showed that the ODS 2 stationary phase increases the retention factor and the resolution, presumably due to an increase in hydrophobic interaction (London dispersion interaction). Although, the resolution has been increased when compared to ODS 1, the time of analysis was too long for semipreparative 
Table 1. Chromatographic Parameters for the Separation of the Three Terpenoids

\begin{tabular}{|c|c|c|c|c|c|c|c|c|}
\hline \multirow[b]{2}{*}{ Column $^{\mathrm{a}}$} & \multirow{2}{*}{$\begin{array}{c}\text { Mobile Phase } \\
\%(y)\end{array}$} & \multicolumn{3}{|c|}{ Retention Factor, k } & \multicolumn{2}{|c|}{$\begin{array}{l}\text { Separation } \\
\text { Factor, } \alpha\end{array}$} & \multicolumn{2}{|c|}{$\begin{array}{l}\text { Resolution, } \\
\text { Rs }\end{array}$} \\
\hline & & $1^{b}$ & $2^{c}$ & $3^{d}$ & $2^{c} / 1^{b}$ & $3^{\mathrm{d}} / 2^{\mathrm{c}}$ & $2^{c} / 1^{b}$ & $3^{\mathrm{d}} / 2^{\mathrm{c}}$ \\
\hline \multirow[t]{14}{*}{ ODS 1} & $\mathrm{MeOH}, 100^{*}$ & 3.42 & 3.42 & 3.42 & 1.00 & 1.00 & - & - \\
\hline & $\mathrm{MeOH} / \mathrm{H}_{2} \mathrm{O}, 90: 10^{*}$ & 6.25 & 6.25 & 6.41 & 1.00 & 1.02 & - & 0.70 \\
\hline & $\mathrm{MeOH} / \mathrm{H}_{2} \mathrm{O}, 85: 15^{*}$ & 12.88 & 12.88 & 13.29 & 1.00 & 1.03 & - & 1.0 \\
\hline & $\mathrm{MeOH}, 100$ & 0.69 & 0.69 & 0.69 & 1.00 & 1.00 & - & - \\
\hline & $\mathrm{MeOH} / \mathrm{H}_{2} \mathrm{O}, 90: 10$ & 0.82 & 0.82 & 0.82 & 1.00 & 1.00 & - & - \\
\hline & $\begin{array}{l}\mathrm{MeOH} / \mathrm{H}_{2} \mathrm{O} / \text { formic acid, } \\
\text { 95:5:1 }\end{array}$ & 3.48 & 3.48 & 3.56 & 1.00 & 1.02 & - & 0.60 \\
\hline & $\begin{array}{l}\mathrm{MeOH} / \mathrm{H}_{2} \mathrm{O} / \text { formic acid, } \\
90: 10: 1\end{array}$ & 5.69 & 5.82 & 5.98 & 1.02 & 1.03 & 0.70 & 0.83 \\
\hline & $\begin{array}{l}\mathrm{MeOH} / \mathrm{H}_{2} \mathrm{O} / \text { formic acid, } \\
\quad 85: 15: 1\end{array}$ & 9.68 & 9.95 & 10.29 & 1.03 & 1.03 & 0.83 & 0.96 \\
\hline & $\begin{array}{l}\mathrm{MeOH} / \mathrm{H}_{2} \mathrm{O} / \text { formic acid, } \\
83: 17: 1\end{array}$ & 11.5 & 11.9 & 12.3 & 1.03 & 1.03 & 1.0 & 1.1 \\
\hline & $\begin{array}{l}\mathrm{MeOH} / \text { ammonium hydrogen } \\
\text { sulfate }(0.005 \mathrm{~mol} / \mathrm{l}), 95: 5\end{array}$ & 11.1 & 11.4 & 11.4 & 1.01 & 1.00 & 0.60 & - \\
\hline & $\begin{array}{l}\mathrm{MeOH} / \text { ammoniun hydrogen } \\
\text { sulfate }(0.005 \mathrm{~mol} / \mathrm{l}), 85: 15\end{array}$ & 9.0 & 9.2 & 9.7 & 1.02 & 1.04 & 0.84 & 0.95 \\
\hline & $\begin{array}{l}\mathrm{ACN} / \mathrm{H}_{2} \mathrm{O} / \text { formic acid, } \\
90: 10: 1\end{array}$ & 3.42 & 3.42 & 3.42 & 1.00 & 1.00 & - & - \\
\hline & $\begin{array}{l}\mathrm{ACN} / \mathrm{H}_{2} \mathrm{O} / \text { formic acid, } \\
85: 15: 1\end{array}$ & 4.80 & 4.80 & 4.80 & 1.00 & 1.00 & - & - \\
\hline & $\begin{array}{l}\mathrm{ACN} / \mathrm{H}_{2} \mathrm{O} / \text { formic acid, } \\
80: 20: 1\end{array}$ & 5.0 & 5.15 & 5.20 & 1.03 & 1.00 & 0.70 & - \\
\hline ODS 2 & $\begin{array}{l}\mathrm{MeOH} / \mathrm{H}_{2} \mathrm{O} / \text { formic acid, } \\
85: 15: 1\end{array}$ & 17.1 & 17.7 & 18.4 & 1.03 & 1.04 & 1.0 & 1.5 \\
\hline
\end{tabular}

${ }^{a}$ ODS $1=250 \mathrm{~mm} \times 10 \mathrm{~mm}$ i.d. packed with Spherisorb octadecyl-bonded silica; ODS $2=250 \mathrm{~mm} \times 10 \mathrm{~mm}$ i.d. packed with Spherisorb octadecyl-bonded silica.

${ }^{\mathrm{b}} 1=(-)-(5 \mathrm{R}, 8 \mathrm{~S}, 9 \mathrm{~S}, 10 \mathrm{R})$-cleroda-3,13E-dien-15-oic-acid.

$c_{2}=(-)-(5 \mathrm{~S}, 8 \mathrm{~S}, 9 \mathrm{~S}, 10 \mathrm{R})$-cleroda-3,13E-dien-15-oic-acid.

$\mathrm{d}_{3}=(-)$-kovalenic acid.

*Methylated compounds.

scale work (Figure 2). Thus, the best conditions for isolation of these diterpenes were through the use of the ODS 1 column with $\mathrm{MeOH} / \mathrm{H}_{2} \mathrm{O} /$ formic acid $(85: 15: 1, \mathrm{v} / \mathrm{v} / \mathrm{v})$ as mobile phase. After collecting the fractions, those containing compounds 2 and 3 were submitted to esterification with diazomethane in order to avoid decomposition. On the other hand, compound 1 showed chemical 

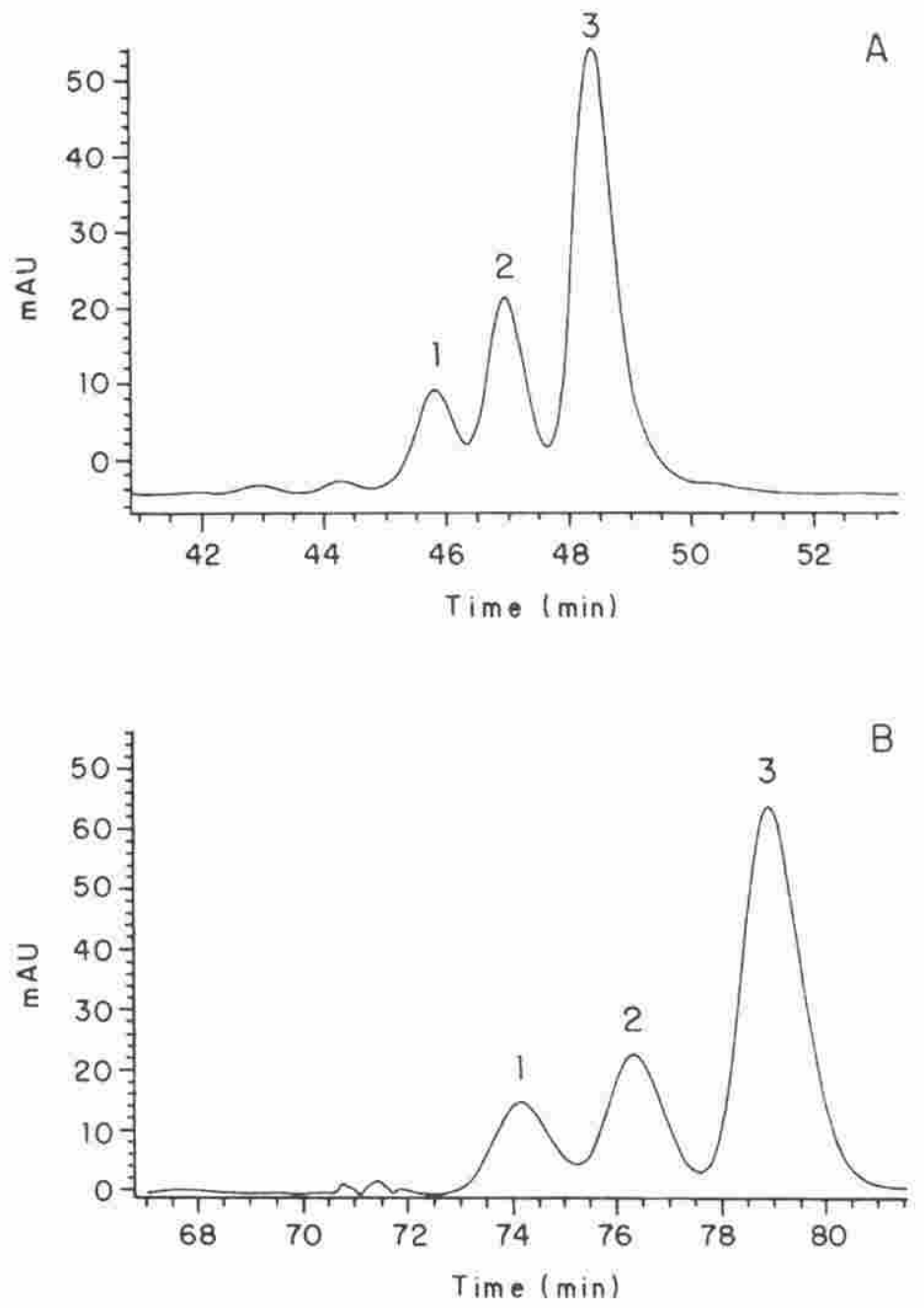

Figure 2. Chromatogram obtained for the diterpenes on A) ODS 1 stationary phase, B) ODS 2 stationary phase. Chromatographic conditions: column $250 \mathrm{~mm} \times 10 \mathrm{~mm}$ i.d. packed with Spherisorb octadecyl-bonded silica, $(5 \mu \mathrm{m})$; mobile phase: $\mathrm{MeOH} / \mathrm{H}_{2} \mathrm{O} /$ formic acid $(85: 15: 1, \mathrm{v} / \mathrm{v} / \mathrm{v})$; UV detection at $240 \mathrm{~nm}$; flow rate at $2 \mathrm{~mL} / \mathrm{min}$. Injection volume: $5 \mu \mathrm{L}$. 
stability, so that it was not necessary to do a derivatization before structural elucidation by ${ }^{1} \mathrm{H}$ and ${ }^{13} \mathrm{C}$ NMR.

Several collected fractions were analyzed by GC/MS in order to evaluate the purity and the identities of the compounds. The (-)-(5R,8S,9S,10R)-cleroda3,13E-dien-15-oic acid (1) was methylated before analysis by GC/MS due to the limitation of the column for acid substances.

\section{ACKNOWLEDGMENTS}

RTN thanks CAPES, CNPq, and FAEP/UNICAMP for fellowships. The authors also thank Dr. C. H. Collins for helpful discussion and suggestions.

\section{REFERENCES}

1. Lee, Y.T.; Langenheim, J.H. Systematics of the genus Hymenaea L.; Chemistry of California Press Ltd.: California, 1975; 1-109.

2. Marsaioli, A.J.; de Leitão Filho, H.F.; Campello, J.P. Phytochemistry 1975, 14, 1882-1883.

3. Neves, P.C.A.; Zanini, J.C.; Medeiros, Y.S.; Yunes, R.A.; Calixto, J. B. Phytother. Res. 1993, 5, 356-359.

4. Oliveira, W. Galileu 1999, 59-61.

5. Stubblebine, W.H.; Langenheim, J.H. Acta Amazonica 1980, 10, 293-309.

6. Cunningham, A.; Martin, S.S.; Langenheim, J.H. Phytochemistry 1973, 12, 633-635.

7. Khoo, S.F.; Oehlschlager, A.C.; Ourisson, G. Tetrahedron 1973, 29, 3379 3388 .

8. Nakano, T.; Djerassi, C. J. Org. Chem 1961, 26, 167-173.

9. Hugel, G.; Lods, L.; Mellor, J.M.; Theobald, D.W.; Ourisson, G. Bull. Soc. Chim. Fr. 1965, 32, 2882-2887.

10. Hugel, G.; Lods, L.; Mellor, J.M.; Theobald, D.W.; Ourisson, G. Bull. Soc. Chim. Fr. 1965, 32, 2888-2894.

11. Hugel, G.; Lods, L.; Mellor, J.M.; Theobald, D.W.; Ourisson, G. Bull. Soc. Chim. Fr. 1965, 32, 2903-2908.

12. Imamura, P.M.; Marsaioli, A.J.; Barata, L.E.S.; Rúveda, E.A. Phytochemistry $1977,16,1842-1844$.

13. Morin, Ph.; Caude, M.; Richard, H.; Rosset, R. J. Chromatogr. 1986, 363, 57-69.

14. van Beek, T.A.; Kleis, R.; Lelyveld, G.P.; de Groot, A.E. Chromatographia $1989,28,126-128$.

15. Scalia, S.; Francis, G.W. Chromatographia 1989, 28, 129-132. 
16. Morin, P.H.; Caude, M.; Richard, H.; Rosset, R. Analysis 1985, 13, 196217.

17. Harvey, S.D.; Campbell, J.A.; Kelsey, R.G.; Vance, N.C. J. Chromatogr. 1991, 587, 300-305.

18. Abidi, S.L.; Mounts, T.L. J. Chromatogr. A 1997, 782, 25-32.

19. Nogueira, R.T; Shepherd, G.; Laverde Jr., A.; Marsaioli, A.J.; Imamura, P.A. Phytochemistry, (in press).

Received July 1, 2001

Accepted August 1, 2001

Manuscript 5603 
Copyright $@ 2003$ EBSCO Publishing 